\title{
Utilization of Basic-Event Statistical Independence in Simplifying the Uncertainty Analysis of Fault Trees
}

\author{
Ali M. A. Rushdi and Muhammad A. Al-Qwasmi \\ Department of Electrical and Computer Engineering, Faculty of Engineering, King Abdulaziz \\ University, P. O. Box 80204, Jeddah 21589, Saudi Arabia \\ arushdi@kau.edu.sa
}

\begin{abstract}
Analysis of fault trees used in modelling computer system security is typically based on orthogonalization of a Boolean expression as well as preservation of existing statistical independencies. This note shows that careful utilization of statistical independencies is beneficial not only for evaluating the mean value of the top-event probability but also for quantifying its uncertainty. A demonstrative example indicates that such utilization leads to a dramatic reduction in the number of coefficients calculated, as well as a significant simplification of the calculations needed for each of them.
\end{abstract}

Keywords: Fault-tree analysis; Computer system security; Statistical independence; Uncertainty quantification; Doubly-stochastic modelling.

\section{Introduction}

The fault-tree model, a traditional reliability tool ${ }^{[1-5]}$, is now being used also in the analysis and design of security systems [6-8]. Sometimes, fault trees are unnecessarily renamed as attack trees or attack-defense trees for this particular application ${ }^{[9-11] .}$ Analysis of fault trees is typically achieved in the Boolean domain followed by a transform to the probability domain that can be performed directly, on a one-to-one basis, if the success or failure expression obtained in the Boolean domain is a Probability-Ready Expression $(\mathrm{PRE})^{[12-16]}$, i.e., if it is an expression in which

a) All ANDed subexpressions are statistically independent,

b) All ORed subexpressions are disjoint (orthogonal).

While there are literally hundreds of methods to introduce characteristic (b) of orthogonality (disjointness) into a Boolean expression (see, e.g., Bennetts [17, 18] Abrahams [19], Dotson and Gobien ${ }^{[20]}$, and Rushdi ${ }^{[21]}$ ) there is no way to induce characteristic (a) of statistical independence. The best that one can do is to observe statistical independence when it exists, and then take care to preserve it and take advantage of it. The aim of this note is to demonstrate that statistical independence is beneficial not only in the evaluation of the nominal value of top-event probability but also in computing the uncertainty in that probability.

\section{Uncertainty Analysis of Fault Trees}

Analysis of a fault tree results in a PRE expression for the indicator variable $\mathrm{S}^{-}$of the top event in terms of the indicator variables $X$ of the basic events. The expression $\left.\mathrm{S}^{-} \mathrm{X}\right)$ is transformed to an expression $\mathrm{Q}(\mathrm{q})$ of the topevent probability in terms of the basic-event 
probabilities q. To quantify uncertainty in $\mathrm{Q}$, we use a doubly-stochastic model in which probabilities are treated as random variables ${ }^{[22-25]}$. We assume that the basic event probabilities q_i are random variables of mean values and variances given respectively by:

$v_{i 1}=E\left\{q_{i}\right\}, \quad 1 \leq i \leq n$.

$v_{i 2}=E\left\{\left(q_{i}-v_{i 1}\right)^{2}\right\}=E\left\{q_{i}^{2}\right\}-v_{i 1}^{2} . \quad 1 \leq$

$i \leq n$.

The mean value of the top-event probability is [22]

$\mu_{1}=E\{Q(\boldsymbol{q})\}=\left.Q(\boldsymbol{q})\right|_{\boldsymbol{q}=\boldsymbol{v}_{\mathbf{1}}}$,

while its variance is given by [22]

$$
\begin{aligned}
& \mu_{2}=\sum_{1 \leq i \leq n} C_{i}^{2} v_{i 2} \\
& +\sum \sum_{1 \leq i<j \leq n} C_{i j}^{2} v_{i 2} v_{j 2} \\
& +\sum \sum \sum_{\substack{1 \leq i<j<k \leq n \\
+C_{12}}} C_{i j k}^{2} v_{12} v_{22} \ldots v_{n 2} .
\end{aligned}
$$

where

$$
\begin{aligned}
& C_{i}=\left(\partial Q / \partial q_{i}\right)_{\boldsymbol{q}=\boldsymbol{v}_{\mathbf{1}}}=\left(\left.Q(\boldsymbol{q})\right|_{q_{i}=1}-\right. \\
& \left.\left.Q(\boldsymbol{q})\right|_{q_{i}=0}\right)_{\boldsymbol{q}=\boldsymbol{v}_{\mathbf{1}}} \\
& C_{i j}=\left(\partial^{2} Q / \partial q_{i} \partial q_{j}\right)_{\boldsymbol{q}=\boldsymbol{v}_{\mathbf{1}}} \\
& \quad=\left(\left.Q(\boldsymbol{q})\right|_{q_{i}=q_{j}=1}-\left.Q(\boldsymbol{q})\right|_{q_{i}=1, q_{j}=0}-\right. \\
& \left.\left.Q(\boldsymbol{q})\right|_{q_{i}=0, q_{j}=1}+\left.Q(\boldsymbol{q})\right|_{q_{i}=q_{j}=0}\right)_{\boldsymbol{q}=\boldsymbol{v}_{\mathbf{1}}}
\end{aligned}
$$

(6)

$$
\begin{aligned}
& C_{i j k}=\left(\partial^{3} Q / \partial q_{i} \partial q_{j} \partial q_{k}\right)_{\boldsymbol{q}=\boldsymbol{v}_{\mathbf{1}}} \\
& =\left(\left.Q(\boldsymbol{q})\right|_{q_{i}=q_{j}=q_{k}=1}-\left.Q(\boldsymbol{q})\right|_{q_{i}=q_{j}=1 . q_{k}=0}-\right. \\
& \left.Q(\boldsymbol{q})\right|_{q_{i}=q_{k}=1 . q_{j}=0}-\left.Q(\boldsymbol{q})\right|_{q_{j}=q_{k}=1, q_{i}=0}+ \\
& \left.Q(\boldsymbol{q})\right|_{q_{i}=1, q_{j}=q_{k}=0}+\left.Q(\boldsymbol{q})\right|_{q_{j}=1, q_{i}=q_{k}=0}+ \\
& \left.Q(\boldsymbol{q})\right|_{q_{k}=1, q_{i}=q_{j}=0}- \\
& \left.\left.Q(\boldsymbol{q})\right|_{q_{i}=q_{j}=q_{k}=0}\right)_{\boldsymbol{q}=\boldsymbol{v}_{\mathbf{1}}} .
\end{aligned}
$$

and so on. The number of terms in (4) is $\left(\begin{array}{l}n \\ 1\end{array}\right)+\left(\begin{array}{l}n \\ 2\end{array}\right)+\cdots+\left(\begin{array}{l}n \\ n\end{array}\right)=2^{n}-1$.

which is exponential and hence undesirably large.

\section{Utilization of Statistical Independence}

In many problems of fault tree analysis, the assumption of statistical independence among basic events is valid. If care is taken not to spoil the characteristics of statistical independence, one might arrive at an expression for the top-event probability of the form

$Q=Q\left(Q_{1}\left(\boldsymbol{q}_{1}\right), Q_{2}\left(\boldsymbol{q}_{2}\right), \ldots, Q_{m}\left(\boldsymbol{q}_{\boldsymbol{m}}\right)\right)$,

where $Q_{1}, Q_{2}, \ldots, Q_{m}$ are statistically independent probabilities, thanks to being functions of disjoint subsets $\boldsymbol{q}_{1}, \boldsymbol{q}_{2}, \ldots \boldsymbol{q}_{m}$ of the set of basic-event probabilities $\boldsymbol{q}$. These subsets are assumed to contain $n_{1} . n_{2} \ldots . n_{m}$ basic events, respectively, where $n_{1}+n_{2}+$ $\ldots+n_{m}=n$.

Equation (9) can be used to obtain the mean value and uncertainty of $Q$ in terms of those of $Q_{1}, Q_{2}, \ldots, Q_{n}$, which in turn are readily obtained in terms of those of $\boldsymbol{q}_{1}, \boldsymbol{q}_{2}, \ldots$, and $\boldsymbol{q}_{\boldsymbol{m}}$. A great saving is achieved in the number of coefficients involved, since it reduces from that in (8) to

$$
\begin{aligned}
\sum_{j=1}^{m}\left(2^{n_{j}}-1\right)+\left(2^{m}-1\right) \\
=\left(\sum_{j=1}^{m} 2^{n_{j}}\right)+2^{m}-(m+1)
\end{aligned}
$$

The saving in even more substantial since the evaluation of coefficients becomes much simpler as it involves significantly fewer variables. The savings gained are now demonstrated via the following illustrative example. 


\section{Example}

Consider the fault tree in Fig. 1, with its top and basic events interpreted in Table 1. The indicator variable $\bar{S}$ of the top event for this fault tree can be expressed in terms of those of the basic events as

$\bar{S}=\bar{X}_{1} \vee \bar{X}_{2} \vee \bar{X}_{3} \vee \bar{X}_{4} \vee \bar{X}_{5} \vee \bar{X}_{6} \bar{X}_{7} \bar{X}_{8}$.

Henceforth, the basic events are assumed to be statistically independent. Expression (11) for $\bar{S}$ can be rewritten in the PRE form

$\bar{S}=\bar{X}_{1} \vee X_{1} \bar{X}_{2} \vee X_{1} X_{2} \bar{X}_{3} \vee X_{1} X_{2} X_{3} \bar{X}_{4} \vee$

$X_{1} X_{2} X_{3} X_{4} \bar{X}_{5} \vee X_{1} X_{2} X_{3} X_{4} X_{5} \bar{X}_{6} \bar{X}_{7} \bar{X}_{8}$,

which corresponds to the following expression for the top-event probability:

$Q(\boldsymbol{q})=q_{1}+p_{1} q_{2}+p_{1} p_{2} q_{3}+p_{1} p_{2} p_{3} q_{4}+$

$p_{1} p_{2} p_{3} p_{4} q_{5}+p_{1} p_{2} p_{3} p_{4} p_{5} q_{6} q_{7} q_{8}$.

Alternatively, the complement of (11) is written as

$S=X_{1} X_{2} X_{3} X_{4} X_{5}\left(X_{6} \vee X_{7} \vee X_{8}\right)$,

which results in the following unusually simple expression for the top-event probability:

$Q(\boldsymbol{q})=1-p_{1} p_{2} p_{3} p_{4} p_{5}\left(1-q_{6} q_{7} q_{8}\right)$.
Further analysis via (13) demands the calculation of $2^{8}-1=255$ cumbersome coefficients. Instead, we continue the analysis by rewriting (15) as

$Q(\boldsymbol{q})=1-r_{a} r_{b}$

where $r_{a}, r_{b}$, are statistically- independent quantities given by:

$$
\begin{aligned}
& r_{a}=p_{1} p_{2} p_{3} p_{4} p_{5}=\left(1-q_{1}\right)\left(1-q_{2}\right)(1- \\
& \left.q_{3}\right)\left(1-q_{4}\right)\left(1-q_{5}\right) \\
& r_{b}=1-q_{6} q_{7} q_{8},
\end{aligned}
$$

Now, the mean value of the top-event probability is

$\mu_{1}=1-v_{a 1} v_{b 1}$,

Where

$$
\begin{aligned}
& v_{a 1}=\left(1-v_{11}\right)\left(1-v_{21}\right)\left(1-v_{31}\right)(1- \\
& \left.v_{41}\right)\left(1-v_{51}\right), \\
& v_{b 1}=1-v_{61} v_{71} v_{81},
\end{aligned}
$$

The uncertainty in the top-event probability is obtained via the following equations, which involves the evaluation of $(3+31+7)=41$ much simpler coefficients rather than the aforementioned coefficients.

$\mu_{2}=c_{a}^{2} v_{a 2}+c_{b}^{2} v_{b 2}+c_{a b}^{2} v_{a 2} v_{b 2}$.

Where $c_{a}=-v_{b 1}, c_{b}=-v_{a 1}, c_{a b}=-1$.

$v_{a 2}=c_{1}^{2} v_{12}+c_{2}^{2} v_{22}+c_{3}^{2} v_{32}+c_{4}^{2} v_{42}+c_{5}^{2} v_{52}+c_{12}^{2} v_{12} v_{22}+c_{13}^{2} v_{12} v_{32}+c_{14}^{2} v_{12} v_{42}+$ $c_{15}^{2} v_{12} v_{52}+c_{23}^{2} v_{22} v_{32}+c_{24}^{2} v_{22} v_{42}+c_{25}^{2} v_{22} v_{52}+c_{34}^{2} v_{32} v_{42}+c_{35}^{2} v_{32} v_{52}+c_{45}^{2} v_{42} v_{52}+$ $c_{123}^{2} v_{12} v_{22} v_{32}+c_{124}^{2} v_{12} v_{22} v_{42}+c_{125}^{2} v_{12} v_{22} v_{52}+c_{134}^{2} v_{12} v_{32} v_{42}+c_{135}^{2} v_{12} v_{32} v_{52}+$ $c_{145}^{2} v_{12} v_{42} v_{52}+c_{234}^{2} v_{22} v_{32} v_{42}+c_{235}^{2} v_{22} v_{32} v_{52}+c_{245}^{2} v_{22} v_{42} v_{52}+c_{345}^{2} v_{32} v_{42} v_{52}+$ $c_{1234}^{2} v_{12} v_{22} v_{32} v_{42}+c_{1235}^{2} v_{12} v_{22} v_{32} v_{52}+c_{1245}^{2} v_{12} v_{22} v_{42} v_{52}+c_{1345}^{2} v_{12} v_{32} v_{42} v_{52}+$ $c_{2345}^{2} v_{22} v_{32} v_{42} v_{52}+c_{12345}^{2} v_{12} v_{22} v_{32} v_{42} v_{52}$,

where

$$
\begin{aligned}
& c_{1}=-\left(1-v_{21}\right)\left(1-v_{31}\right)\left(1-v_{41}\right)\left(1-v_{51}\right), c_{2}=-\left(1-v_{11}\right)\left(1-v_{31}\right)\left(1-v_{41}\right)\left(1-v_{51}\right), \\
& c_{3}=-\left(1-v_{11}\right)\left(1-v_{21}\right)\left(1-v_{41}\right)\left(1-v_{51}\right), c_{4}=-\left(1-v_{11}\right)\left(1-v_{21}\right)\left(1-v_{31}\right)\left(1-v_{51}\right), \\
& c_{5}=-\left(1-v_{11}\right)\left(1-v_{21}\right)\left(1-v_{31}\right)\left(1-v_{41}\right), c_{12}=\left(1-v_{31}\right)\left(1-v_{41}\right)\left(1-v_{51}\right), \\
& c_{13}=\left(1-v_{21}\right)\left(1-v_{41}\right)\left(1-v_{51}\right), c_{14}=\left(1-v_{21}\right)\left(1-v_{31}\right)\left(1-v_{51}\right), \\
& c_{15}=\left(1-v_{21}\right)\left(1-v_{31}\right)\left(1-v_{41}\right), c_{23}=\left(1-v_{11}\right)\left(1-v_{41}\right)\left(1-v_{51}\right),
\end{aligned}
$$




$$
\begin{aligned}
& c_{24}=\left(1-v_{11}\right)\left(1-v_{31}\right)\left(1-v_{51}\right), c_{25}=\left(1-v_{11}\right)\left(1-v_{31}\right)\left(1-v_{41}\right), \\
& c_{34}=\left(1-v_{11}\right)\left(1-v_{21}\right)\left(1-v_{51}\right), c_{35}=\left(1-v_{11}\right)\left(1-v_{21}\right)\left(1-v_{41}\right), \\
& c_{45}=\left(1-v_{11}\right)\left(1-v_{21}\right)\left(1-v_{31}\right), c_{123}=-\left(1-v_{41}\right)\left(1-v_{51}\right), c_{124}=-\left(1-v_{31}\right)\left(1-v_{51}\right), \\
& c_{125}=-\left(1-v_{31}\right)\left(1-v_{41}\right), c_{134}=-\left(1-v_{21}\right)\left(1-v_{51}\right), c_{135}=-\left(1-v_{21}\right)\left(1-v_{41}\right), \\
& c_{145}=-\left(1-v_{21}\right)\left(1-v_{31}\right), c_{234}=-\left(1-v_{11}\right)\left(1-v_{51}\right), c_{235}=-\left(1-v_{11}\right)\left(1-v_{41}\right), \\
& c_{245}=-\left(1-v_{11}\right)\left(1-v_{31}\right), c_{345}=-\left(1-v_{11}\right)\left(1-v_{21}\right), c_{1234}=\left(1-v_{51}\right), c_{1235}=\left(1-v_{41}\right), \\
& c_{1245}=\left(1-v_{31}\right), c_{1345}=\left(1-v_{21}\right), c_{2345}=\left(1-v_{11}\right), c_{12345}=1 . \\
& v_{b 2}=c_{6}^{2} v_{62}+c_{7}^{2} v_{72}+c_{8}^{2} v_{82}+c_{67}^{2} v_{62} v_{72}+c_{68}^{2} v_{62} v_{82}+c_{78}^{2} v_{72} v_{82}+c_{678}^{2} v_{62} v_{72} v_{82}, \quad(22) \\
& \text { where } c_{6}=-v_{71} v_{81}, c_{7}=-v_{61} v_{81}, c_{8}=-v_{61} v_{71}, c_{67}=-v_{81}, c_{68}=-v_{71}, c_{78}=-v_{61} \\
& \text { and } c_{678}=-1 .
\end{aligned}
$$

\begin{tabular}{|c|c|c|}
\hline & $\begin{array}{l}\text { Indicator } \\
\text { Variable }\end{array}$ & Indicated Event \\
\hline Top Event & $\bar{S}$ & The adversary illegally gains access to an industrial secret of the competitor. \\
\hline \multirow{8}{*}{$\begin{array}{c}\text { Basic } \\
\text { Events }\end{array}$} & $\bar{X}_{1}$ & The adversary breaks into the computer system of the competitor. \\
\hline & $\bar{X}_{2}$ & The adversary secretly steals a written document containing the secret. \\
\hline & $\bar{X}_{3}$ & $\begin{array}{l}\text { The adversary openly obtains the secret through an armed robbery of the competitor's } \\
\text { headquarters. }\end{array}$ \\
\hline & $\bar{X}_{4}$ & The adversary obtains the secret by bribing an employee of the competitor. \\
\hline & $\bar{X}_{5}$ & The adversary acquires the secret by blackmailing an insider in the competitor's company. \\
\hline & $\bar{X}_{6}$ & $\begin{array}{l}\text { The adversary intercepts a communicated message containing the secret in concealed encrypted } \\
\text { form. }\end{array}$ \\
\hline & $\bar{X}_{7}$ & $\begin{array}{l}\text { The adversary detects presence of the secret and extracts its cipher-text despite its concealment via } \\
\text { steganography. }\end{array}$ \\
\hline & $\bar{X}_{8}$ & The adversary succeeds in his cryptanalysis attack and converts the cipher-text into a plaintext. \\
\hline
\end{tabular}

The above calculations are for nonidentical basic-event probabilities and allow a detailed exploration of the effect of their variation on the nature of top-event probability. For the identical case of $v_{i 1}=$
$10^{-1}, v_{i 2}=10^{-4}$ for $1 \leq i \leq 8$, we obtain the following numerical results:

$$
\begin{aligned}
& v_{a 1}=0.59049, v_{b 1}=0.999, \mu_{1}=0.41010049 \\
& v_{a 2}=0.0002152868, \\
& \mu_{2}=0.000214867
\end{aligned}
$$

Table 1. Meaning of variables indicating top and basic events of the fault tree. 


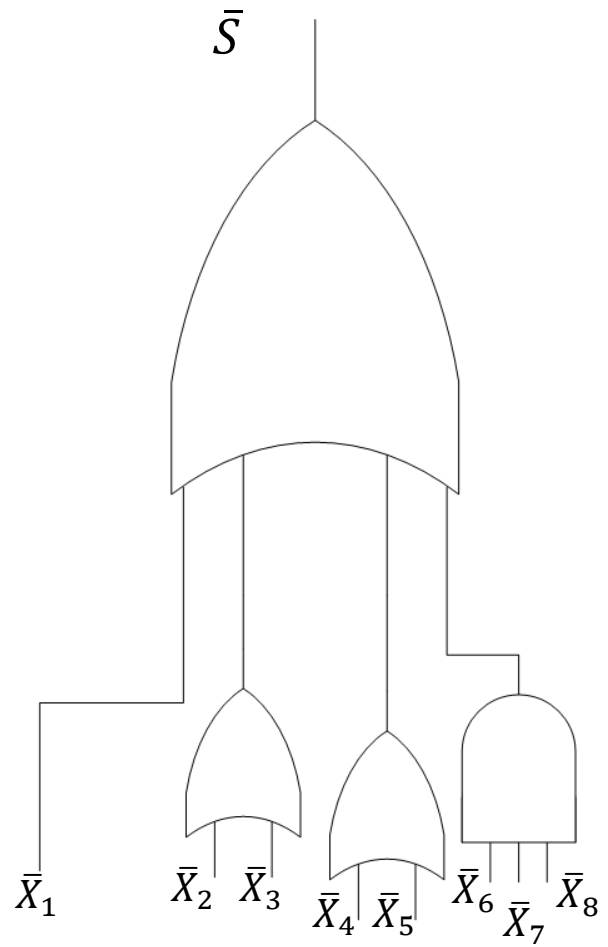

Fig. 1. A typical fault-tree model for a computer security application.

\section{Conclusions}

Careful utilization of statistical independencies in a probability expression is shown to achieve a substantial reduction not only in the computational cost for the mean value of probability but also in that of its variance. This note demonstrated the above reduction in a typical doubly-stochastic faulttree model of computer system security.

\section{References}

[1] Kumamoto, H. (1993), Fault Tree Analysis, In: K. B. Misra (Editor), New Trends in System Reliability Evaluation, Vol. 16, Fundamental Studies in Engineering, Elsevier Science Publishers, Amsterdam, The Netherlands, pp. 249-312.

[2] Xing, L. and Amari, S. V. (2008), Fault Tree Analysis, In K. B. Misra (Editor), Handbook of Performability Engineering, Springer London, pp. 595-620.
[3] Liang, X., Yi, H., Zhang, Y. and Li, D. (2010), Reliability and safety analysis of an underwater dry maintenance cabin, Ocean Engineering, 37(2): 268-276.

[4] Bhangu, N. S., Pahuja, G. L. and Singh, R. (2015), Application of fault tree analysis for evaluating reliability and risk assessment of a thermal power plant, Energy Sources, Part A: Recovery, Utilization, and Environmental Effects, 37(18): 2004-2012.

[ 5] Ruijters, E. and Stoelinga, M. (2015), Fault tree analysis: A survey of the state-of-the-art in modeling, analysis and tools, Computer Science Review, 15: 29-62.

[ 6] Brooke, P. J. and Paige, R. F. (2003), Fault trees for security system design and analysis, Computers \& Security, 22(3): 256-264.

[ 7] Rushdi, A. M. and Ba-Rukab, O. M. (2005), A doublystochastic fault-tree assessment of the probabilities of security breaches in computer systems, Proceedings of the Second Saudi Science Conference, Part Four: Computer, Mathematics, and Statistics, Jeddah, Saudi Arabia, 1-17.

[ 8] Rushdi, A. M. and Ba-Rukab, O. M. (2005), Fault-tree modelling of computer system security, International Journal of Computer Mathematics, 82(7): 805-819. 
[ 9] Grunske, L. and Joyce, D. (2008), Quantitative riskbased security prediction for component-based systems with explicitly modelled attack profiles, Journal of Systems and Software, 81(8): 1327-1345.

[ 10] Saini, V., Duan, Q. and Paruchuri, V. (2008), Threat modelling using attack trees, Journal of Computing Sciences in Colleges, 23(4): 124-131.

[11] Khand, P. A. (2009), System level security modelling using attack trees, Proceedings of the IEEE 2nd International Conference on Computer, Control and Communication, IC4-2009, pp. 1-6.

[12] Rushdi, A. M. and Goda, A. S. (1985), Symbolic reliability analysis via Shannon's expansion and statistical independence, Microelectronics and Reliability, 25(6): 1041-1053.

[13] Rushdi, A. M. and AbdulGhani, A. A. (1993), A comparison between reliability analyses based primarily on disjointness or statistical independence: The case of the generalized Indra network, Microelectronics and Reliability, 33(7): 965-978.

[ 14] Rushdi, A. M. A. and Hassan, A. K. (2015), Reliability of migration between habitat patches with heterogeneous ecological corridors, Ecological Modelling, 304: 1-10.

[15] Rushdi, A. M. A. and Hassan, A. K. (2016), An exposition of system reliability analysis with an ecological perspective, Ecological Indicators, 63: 282295.

[16] Rushdi, A. M. A. and Al-Qwasmi, M. A. (2016), Exposition and comparison of two kinds of a posteriori analysis of fault trees, Journal of King Abdulaziz.
University: Computing and Information Technology, 5 (1).

[ 17] Bennetts, R. G. (1975), On the analysis of fault trees, IEEE Transactions on Reliability, R-24 (3): 175-185.

[ 18] Bennetts, R. G. (1982), Analysis of reliability block diagrams by Boolean techniques, IEEE Transactions on Reliability, R-31(2): 159-166.

[ 19] Abraham, J. A. (1979), An improved algorithm for network reliability, IEEE Transactions on Reliability, R28(1): 58-61.

[ 20] Dotson, W. and Gobien, J. (1979), A new analysis technique for probabilistic graphs, IEEE Transactions on Circuits and Systems, Vol. CAS-26(10): 855-865.

[21] Rushdi, A. M. (1983), Symbolic reliability analysis with the aid of variable-entered Karnaugh maps, IEEE Transactions on Reliability, R-32(2): 134-139.

[22] Rushdi, A. M. (1985), Uncertainty analysis of fault-tree outputs, IEEE Transactions on Reliability, R-34 (5): 458-462.

[ 23] Rushdi, A. M. and Kafrawy, K. F. (1988), Uncertainty propagation in fault-tree analyses using an exact method of moments, Microelectronics and Reliability, 28: 945-965.

[ 24] Kafrawy, K. F. and Rushdi, A. M. (1990), Uncertainty analysis of fault trees with statistically correlated failure data, Microelectronics and Reliability, 30: 157-175.

[25] Bamasak, S. M. and Rushdi, A. M. A. (2016), Uncertainty analysis of fault-tree models for power system protection. Journal of Qassim University: Engineering and Computer Sciences, 8(1): 65-80. 


\section{استخدام الاستقلال الإحصائي للأحداث الأساسية في تيسير تحليل الربية لأشجار الأخطاء}

\section{علي محمد علي رشدي و محمد أحمد القواسمي}

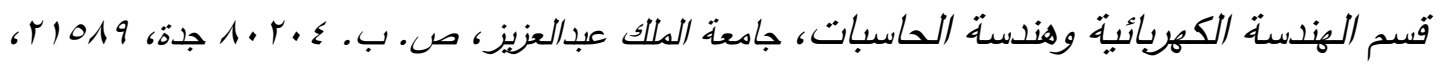
الدملكة العربية السعودية

arushdi@kau.edu.sa

الدستخلص. نقام مقارنة تفصيلية بين مخ الإنسان والماكينات الحاسبة، كما نسرد روايات

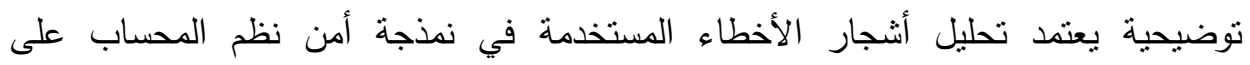
استحداث التعامدية في تعبير بولاني مع المحافظة على ما يكون موجودا في هذا التعبير من التاني استقلالات إحصائية. تظهر هذه العجالة أن العناية باستغلال هذه الاستقلالات الإحصائية لا لا

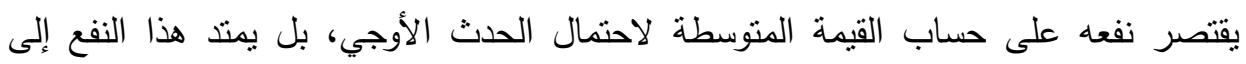
تكمية الريبة في هذا الاحتمال. نظهر من خلال مثال توضيحي أن هذه العناية تؤدي إلى تقليل هائل في عدد المعاملات التي يلزم حسابها فضلا عن تبسيط ملحوظ في الحسابات المطلوبة كل منها.

الكلمات الدفتاحية: تحليل أنثجار الأخطاء، أمن نظم المحساب، الاستقلال الإحصائي، تكمية

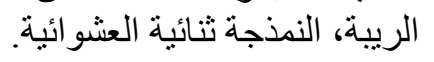


